Marzena Dulowska

Kraków

\title{
SYSTEM OPIEKI POZALEKCYJNEJ NA PRZYKŁADZIE PLACÓWKI W SALZBURGU
}

Temat pracy dotyczy zagadnienia, jakim jest opieka pozaszkolna świadczona $\mathrm{w}$ placówkach oświatowo-wychowawczych dla dzieci w wieku przedszkolnym oraz dzieci i młodzieży w wieku szkolnym. Oferta opieki proponowana jest na bazie dobrowolnego uczestnictwa w zajęciach. W Polsce i Austrii tworzy się rozbudowaną ofertę wychowania pozalekcyjnego, pozaszkolnego i opieki popołudniowej (die Nachmittagsbetreuung), czego przykładem są działania między innymi Gminy Kraków i Gminy Salzburg.

Opiekę popołudniową (die Nachmittagsbetreuung) w ramach pedagogiki czasu wolnego (die Freizeitpädagogik) w Gminie Salzburg oferują między innymi następujące placówki: Akzente, Frauentreffpunkt, Get2Gether, Insel - Haus der Jugend, Corner, Jugendzentrum, Katholische Jugend, Kinder- und Jugendwanwaltschaft, Kinderfreunde, Kinderschutzentrum, Kids-line, Kindertelefon, Kolpinghaus, KOMPASS Ausbildungs- und Berufsberatung, Landesverband für Psychohygiene, Mutter- und Elternbearbeitung, Rainbows, Spektrum, Sucht- und Drogenberatung. Wśród innych placówek opieki popołudniowej wymienić można ogrody zabaw (polski odpowiednik ogrodów jordanowskich ${ }^{1}$ ): Aigen, Gnigl, Innere Stadt, Itzling, Lehen Nord (Glanspitz), Lehen Sud, Leopoldskron, Liefering, Maxglan, Morzg, Schallmoos, Taxham, Spielplatz Hellbrunn, Spielplatz auf der Zistelalm².

Znaczącą w temacie opieki pozaszkolnej jest ustawa z dnia 19.01.2012, jako zmiana rozporządzenia $\mathrm{z}$ dnia $10.12 .1998 \mathrm{r}$. w sprawie promowania i ochrony dzieci i młodzieży w kraju związkowym Salzburg (Salzburger

${ }^{1}$ Zob. H. Śliwowska, K. Wędrowski, Ogrody Jordanowskie, Gł. Księg. Wojsk., Warszawa 1937.

${ }^{2}$ H. Prucher, Jugendschutz. Für Eltern, für Schulen, für Unternehmen, Sozial Land Salzburg, Abteilung Soziales, Salzburg 2008, s. 9-40. 
Jugendgesetz) $)^{3}$. Dzięki powyższej regulacji prawnej każdy młody człowiek ma prawo do ochrony swojego życia, zdrowia fizycznego i psychicznego, a także edukacji, by prezentować odpowiedzialną postawę w rozwoju fizycznym, psychicznym i duchowym. Ustawa ta ma na celu zaspokojenie podstawowego prawa do opieki całodziennej (die Tagesbetreuung): szkolnej (die schulische Betreuung) i pozaszkolnej (die außerschulische Betreuung) oraz rozwoju jednostkowego ${ }^{4}$. W szczególności opiera się na zakazie wszelkiej dyskryminacji wobec dzieci - nadrzędnej wobec ich dobra, natomiast kładzie nacisk na wspieranie wolności dzieci i ich zaangażowania w sprawy dotyczące rozumienia art. 2, 3, 12 i 13 Konwencji o Prawach dziecka 5 . Rozwój młodzieży opiera się na następujących filarach: (1) poradnictwo (wsparcie środowiskowe rodziców), (2) współpraca z publicznymi i prywatnymi instytucjami opiekuńczymi, (3) dostosowanie środków rozwoju jednostki do jej możliwości osobistych i socjalnych, (4) współstanowienie. Ustawa zawiera także szczegółowe wytyczne dotyczące zasad pracy z młodzieża, a także cechy, które powinny zostać rozwijane w placówce opieki pozaszkolnej.

Centra młodzieżowe i miejsca spotkań młodzieży (die Jugendzentren und die Jugendtreffpunkte), to obiekty przeznaczone do kierowania młodzieżą, dając im możliwość racjonalnego i odpowiedzialnego wypoczynku ${ }^{6}$. Obowiązki opiekunów względem podopiecznych w placówkach reguluje natomiast art. 1. i 2. $\S 18^{7}$.

Do podstawowych zależności związanych z jakością opieki pozaszkolnej w Salzburgu, można zaliczyć:

- Poprzez dofinansowanie opieki popołudniowej w Gminie Salzburg, zmniejszają się koszty związane z łożeniem na lekcje dodatkowe dzieci (korepetycje),

- Starania Gminy Salzburg związane są ze zwiększeniem jakości edukacji i opieki,

- Profilaktyka prozdrowotna w Gminie Salzburg połączona jest z regularnymi badaniami z zakresu sprawności fizycznej dzieci,

${ }^{3}$ Gesamte Rechtsvorschrift für Salzburger Jugendgesetz, Fassung vom 19.01.2012, Gesetz vom 10. Dezember 1998 über die Forderung und den Schutz der Jugend im Land Salzburg (Salzburger Jugendgesetz) StF. LGB1 Nr 24/1999 (Blg LT 11. GP: RV 699, 5. Sess; AB 195, 6. Sess).

4 Salzburger Jugendgesetz, Fassung vom 19.01.2012, Art. 1. § 1.

${ }_{5}$ Das Übereinkommen über die Rechte des Kindes, BGB1. Nr. 7/1993, Art. 10 Abs. 2, Bundesgesetzblatt für die Republik Osterreich, 30. Juni 1993, Verlanspostamt 1030 Wien.

${ }_{6}^{6}$ Jugendzentren und Jugendtreffpunkte im Sinn dieses Gesetzes sind Einrichtungen, die dazu bestimmt sind, der Jugend Anleitung und Gelegenheit für eine sinnvolle, den verschiedenen Neigungen entsprechende Freizeitgestaltung zu bieten. Zob. Ibidem, art. $1 . \S 10$.

7 Salzburger Jugendgesetz, Fassung vom 19.01.2012, op. cit., art. 1. i 2. § 18. 
- Instytut Opieki Popołudniowej w Salzburgu koordynuje współpracę placówek opieki pozaszkolnej ze szkołami podstawowymi, ponadpodstawowymi, wyższymi (die Pädagogische Hochschule Salzburg, die Universität Salzburg), a także rodzicami podopiecznych,

- Gmina inwestuje w modernizacje i rozbudowę szkół w Salzburgu - upatruje w niej inwestycje w przyszłość kolejnych pokoleń.

\section{Działalność pedagogiczna placówki Insel - Haus der Jugend}

„WYSPA - dom młodzieży” (INSEL - Haus der Jugend) znajduje się w Salzburgu - mieście północno-zachodniej Austrii. Placówka zapewnia opiekę po zajęciach szkolnych (die Nachmittagsbetreuung) dla dzieci w wieku od 5 do 15 lat w ramach subdyscypliny pedagogiki, jaką jest pedagogika czasu wolnego (Freizeitpädagogik). Próbując wyznaczyć jej porównywalne miejsce wśród polskich typów placówek wychowania pozaszkolnego, można by ją nazwać Pałacem Młodzieży, jednakże pojęcie to nie funkcjonuje w nazewnictwie austriackim. Pojawiają się natomiast jego synonimy, czyli: instytucja opieki nad dziećmi (die Kinderbetreuungseinrichtung), opieka nad dziećmi (die Kinderbetreuung), opieka dzienna (die Tagesbetreuung), a także opieka popołudniowa (die Nachmittagsbetreuung). Zważając na różnice prawne, ekonomiczne i historyczne pomiędzy Polską i Austria, nie można przyrównać do siebie obu pojęć gdyż są inaczej umiejscowione, pomimo podobnych zasad funkcjonowania ${ }^{8}$.

Koncepcja założenia placówki powstała w 1947 roku, związana była zakcją:, ,Ratowania dzieci” (, RettetdieKinder"), organizowaną przezAmerykańskieDowództwo Wojskowe (American Military Government, a dokładniej przez gen. Marka Wayne'a Clarka) W Polsce natomiast okres ten przypada na kryzys pedagogiki po roku 1947 - sztucznie podtrzymywano idee pedagogizmu w monocentrycznym ładzie społecznym? ${ }^{9}$ W miejscu dawnej strzelnicy przy ulicy Alpenstraße powstała placówka opieki nad dziećmi na wzór amerykańskiej. Na przełomie 1948 i 1949 roku odbyły się pierwsze rozmowy pod przewodnictwem dowództwa amerykańskiego, dotyczące stworzenia zakładu opieki nad młodzieżą (die Jugendbetreuungseinrichtung).

${ }^{8}$ Nr. 315 der Beilagen zum stenographischen Protokoll des Salzburger Landtages (4. Session der 13. Gesetzgebungsperiode), Vorlage der Landesregierung, Gesetz über die Kinderbetreuung im Land Salzburg (Salzburger Kinderbetreuungsgesetz $2007 \S 46$ abs. 1).

9 T. Hejnicka-Bezwińska: Kryzys w polskiej pedagogice drugiej połowy XX wieku, w: T. Hejnicka-Bezwińska, Tożsamość pedagogiki-od ortodoksji do heterogeniczności, Wydawnictwo 69, Warszawa 1997, s. 125-154. 
Placówkę pod nazwą „Nowy dom młodzieży” („Neue Haus der Jugend”) otwarto w 1950 roku - wtedy też nastąpiła jej rozbudowa. W kolejnych latach instytucja podpisała umowę najmu z Rządem Federalnym (1951). Pierwsza inicjatywa integracji ze społecznością lokalną Salzburga pojawiła się w 1952 roku, poprzez założenie "Stowarzyszenia dobry sąsiad" („Verein Guter Nachbar") przez Tam Deeringa, oficera Austriackich Działań Młodzieżowych - AYA (Austrian Youth Activities). W 1955 roku placówka oferowała pięcioklasową szkołę z internatem dziennym ${ }^{10}$ (das Tagesinternat) dla dzieci „,z kluczem na szyi” (die Schlüsselkinder) - pozostawionych po szkole bez opieki. Przy wsparciu młodzieży, a także współpracy ze Stowarzyszeniem Dobry Sąsiad - Dom Młodzieży organizował letnie schronisko młodzieżowe dla dzieci na terenie budynków szkoły w okresie wakacji. Wtedy też powstał pierwszy klub sportowy grający w piłkę nożna, działający przy placówce, pod nazwą: "Stowarzyszenie dobrego sąsiada" (Fußballklub „Verein Guter Nachbar"). W 1980 roku dobudowano do niej dwa pomieszczenia oraz warsztat ceramiczny. Rok później odebrano placówce możliwość prowadzenia internatu dziennego. Po kilku latach nastąpiła kolejna rozbudowa instytucji (1984), powstał plac zabaw, basen, boiska sportowe, sala gimnastyczna, audytorium, warsztat majsterkowicza dla dzieci oraz biblioteka. Główną ideą centrum było połączenie nauki szkolnej z wypoczynkiem. W 1986 planowano zmianę placówki na specjalna, szkołę Montessori lub sanatorium (1987) - co nie doszło do skutku. W 1990 roku placówkę przejął obecny dyrektor - Heimo Weilharter - pedagog czasu wolnego (die Freizeitpädagogik), wykładowca na uniwersytecie w Salzburgu i Akademii Pedagogicznej w Salzburgu, ekspert Ajurweda ${ }^{11}$ i NLP ${ }^{12}$, szef Budoakademie - trener karate, Tai Chi, Qi Gong i Kendo, a także Coach ${ }^{13}$.

Założenia organizacyjne placówki nie zmieniały się na przestrzeni wieków - zawsze miała ona na celu pomoc dzieciom, rozwijanie w nich

${ }^{10}$ Internaty dzienne nigdy nie funkcjonowały w Polsce.

${ }^{11}$ Ajurweda - (ang. Ayurveda) - system medycyny indyjskiej rozwinięty w starożytności. Termin ajurweda jest złożeniem słów aj uh - „życie” oraz weda, oznacza „wiedzę o życiu” lub "przebieg życia”. Ajurweda zajmuje się zdrowiem fizycznym, psychicznym i duchowym. Jako koncepcja zdrowia i terapii jest uznawana od 1979 przez Swiatową Organizację Zdrowia.

12 Programowanie neurolingwistyczne - (ang. neuro-linguistic programming, NLP) - wiedza na temat subiektywnego doświadczania, modelu skutecznej komunikacji oraz instrumentu zmiany osobistej. Zbiór technik komunikacji nastawionych na tworzenie i modyfikowanie wzorców postrzegania i myślenia u ludzi. Nazwa została wymyślona przez Johna Grindera i Richarda Bandlera, aby podkreślić postulowane powiązanie między procesami neurologicznymi (,neuro'), językiem (,lingwistyczne') i wzorcami zachowań, którymi ludzie się kierują (,programowanie').

${ }^{13}$ H. Mantl, H. Weilharter, INSEL 50 Jahre. Kinder und Jugendinsel - Haus der Jugend, Verlag Ultimo, Akzente Salzburg 1997, s. 9-12. 
potencjału, uzdolnień, a także łączenie nauki z przyjemnością, zabawą i sportem.

Do jej podstawowych celów edukacyjnych należą:

1. koncentracja na znaczeniu jednostki oraz jej społecznych możliwości w obrębie grupy;

2. indywidualizacja procesu społecznego uczenia się - różnicowanie na poziomie osobistym i grupowym.

INSEL - Haus der Jugend opiera się ona na trzech filarach, regulujących działalność opiekunów w placówce, należą do nich:

1. nauka i zabawa,

2. wspólne dorastanie - wspólna integracja,

3. umacnianie ludzi - poszerzanie perspektyw.

Filar pierwszy łączący naukę z zabawą opiera się na rozwijaniu takich umiejętności wychowawców, jak:

- Szkolenie z zakresu kompetencji i refleksji nad zachowaniem w stosunku do nauki uczniów i uczennic,

- Rozwój zdolności skutecznego zarządzania czasem i nauka,

- Wspieranie umiejętności czytania przez uczniów,

- Nauczanie podstawowych technik uczenia się i pracy,

- Wplatanie elementów gier edukacyjnych do zajęć w czasie wolnym.

- Następny filar dotyczący wspólnego wzrastania i zarazem integracji podopiecznych, kładzie nacisk na poniższe działania opiekunów:

- Zrozumienie procesów związanych z nauką szkolną oraz pozaszkolną - nadobowiązkową w środowisku,

- Gromadzenie informacji z zakresu powiązań z partnerami współpracującymi w środowiskach szkolnych i pozaszkolnych,

- Praca nad strukturą komunikacji i współpracy z nauczycielami i rodzicami,

- Nabywanie umiejętności projektowania przestrzeni społecznej.

- Filar trzeci odnoszący się do umacniania wychowanków oraz poszerzania ich perspektyw, reguluje poniższe kwestie organizacyjne placówki:

- Trening rozwiązywania konfliktów oraz sposoby reagowania w sytuacjach konfliktowych,

- Wykrywanie i zmiana form przemocy i agresji oraz ich modyfikacja,

- Przekazywanie wiedzy o seksualności - specyfika pracy z obiema płciami,

- Wspieranie zainteresowań uczennic i uczniów innymi kulturami,

- Gromadzenie wiedzy o aspektach prawnych opieki dziennej.

Od pracowników INSEL oczekuje się dodatkowych kwalifikacji z zakresu pedagogiki czasu wolnego oraz opieki popołudniowej. Do 
podstawowego wykształcenia pedagoga placówki należy: posiadanie wiedzy o programie szkolnym, umiejętności z dziedziny pedagogiki czasu wolnego i opieki popołudniowej na poziomie osobowości, poziomie działania, poziomie instytucjonalnym, a także ich realizacja $\mathrm{w}$ praktyce. Celem zakwalifikowania się do aktywnej opieki popołudniowej (po zajęciach szkolnych), pedagog powinien posiadać:

- umiejętności wspierania i promowania rozwoju dzieci i młodzieży $\mathrm{w}$ dziedzinie rozwoju osobistego podczas nauki w grupie,

- wiedzę z zakresu profesjonalnego projektowania czasu na naukę i wypoczynek,

- umiejętność rozwoju modelu opieki popołudniowej w połączeniu ze szkołami partnerskimi i instytucjami pozaszkolnymi.

Druga istotna kwestia dotyczy kwalifikacji zawodowych pedagogów oraz ich zastosowania w pracy z dziećmi. Dotyczą one pedagogów czasu wolnego (Freizeitpädagoge) w zakresie szkolnej opieki popołudniowej. Powyższe kwalifikacje stwarzają możliwość zatrudnienia w instytucjach świadczących opiekę popołudniową przez władze lokalne i stowarzyszenia oraz inne instytucje pracujące $\mathrm{z}$ młodzieżą. Warunkiem rozpoczęcia pracy zawodowej jest ukończenie stażu, prowadzonego w czterech blokach po 32 lekcje (tj. 128 godzin) przy współpracy z opiekunem praktyk ${ }^{14}$.

Wyspa - dom młodzieży oferuje wszechstronną opiekę nad dziećmi od 5 do 15 roku życia. W przyjaźnie zaprojektowanym środowisku, w rodzinnej atmosferze dla zajęć pozaszkolnych. Jest przestronnym obiektem otoczonym zielenią na obszarze 1,5 ha, posiada łącznie 10 tematycznych pomieszczeń do opieki nad dziećmi i młodzieża, a także prowadzi terapię domową. Na terenie INSEL znajdują się: trampolina, basen, publicznie dostępny skate park, dwa duże ogrody, wzgórza, szałas, „wagon bajek” (Märchenwaggon), pracownia garncarska, ogród Zen, boiska, amfiteatr, sala gimnastyczna, ścianka wspinaczkowa i park linowy. Placówka posiada ponadto bibliotekę, bilard i pracownię komputerową z dostępem do Internetu (z zabezpieczeniami ograniczającymi dostępne treści). Prowadzi się w niej kompleksowe kursy i szkolenia prozdrowotne, zgodnie z zasadami taoizmu ${ }^{15}$. Celem działań na rzecz zdrowia i regularnej praktyki od ruchu artystycznego do całkowitej harmonizacji poprzez właściwe działania jest rozwój siły życiowej.

W placówce kładzie się nacisk na pobudzanie w wychowankach takich wartości, jak: odporność, kreatywność, równość, konsekwencja, wytrzymałość, cierpliwość, gotowość do podejmowania wyzwań, wolność, aktywność w bezpiecznej atmosferze.

${ }^{14}$ D. Anke, S. Klein, S. Schlinske, Die Insel, Grundschule, Braunschweig 1967, s. 29-42.

15 Taoizm (obok konfucjonizmu) był jednym z dwóch najważniejszych systemów filozoficzno-religijnych w Chinach. 


\section{Powiązania instytucjonalne placówki}

Dom młodzieży współpracuje z Wyższą Szkołą Pedagogiczną w Salzburgu (PH - Pädagogischen Hochschule Salzburg), udostępniając jej studentom miejsce praktyki dziennej. W odpowiedzi na szczególne obawy rodziców w obszarze współczesnej edukacji, szkoła wyższa wraz ze stowarzyszeniem Dobry sąsiad - Wyspa dom młodzieży rozpoczęły współpracę. Nawiązano ją w celu stworzenia miejsc praktyk dla studentów pedagogiki. Wyższa Szkoła Pedagogiczna otworzyła centrum doskonalenia kompetencji opieki popołudniowej i pedagogiki czasu wolnego. Wraz z Wyspą - domem młodzieży tworzy ona miejsca praktyk popołudniowych. W 2008 roku rektor dr J. Sampl i dyrektor regionalny do spraw Młodzieży W. Schick zaakcentowali rolę pełnej opieki dziennej, dostosowanej do potrzeb współczesnego społeczeństwa.

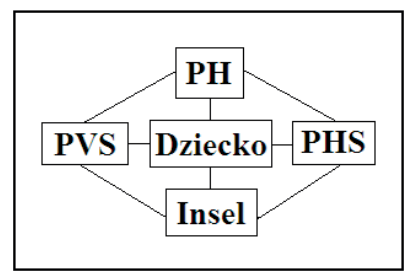

Rysunek 1. Miejsce jednostki w strukturze współpracy instytucji edukacyjno-opiekuńczych w Salzburgu

\footnotetext{
PH - Pädagogische Hochschule (Wyższa Szkoła Pedagogiczna)

PHS - Praxisvolksschule (praktyki w Szkole Podstawowej)

PVS - Praxishauptschule (praktyki w Szkole Ponadpodstawowej, 5-9 klasa).

Źródło: opracowanie własne
}

Współpraca między Wyższą Szkołą Pedagogiczną i Wyspą - domem młodzieży jest partnerstwem ekspertów z zakresu oświaty, w obszarach szkoły, edukacji społecznej, pedagogiki czasu wolnego. Łączy studia i wykształcenie praktyczne $\mathrm{w}$ obszarze pedagogiki czasu wolnego i opieki popołudniowej nad dziećmi i młodzieżą. Dotychczasowe filary wykształcenia praktycznego - szkolnego na Wyższej Szkole Pedagogicznej (Pädagogische Hochschule), podczas praktykach w Szkole Podstawowej (Praxisvolksschule), Szkole Głównej (Praxishauptschule - szkole ponadpodstawowej), a także w szkołach państwowych, zostały poszerzone wraz z otwarciem miejsc praktyki dziennej w Insel, co stało się ważnym elementem praktycznego wsparcia pracy pedagogicznej. Obrazowo przedstawia to rysunek 1 . 


\section{Podsumowanie}

Analizując zasady funkcjonowania placówki Insel - Haus der Jugend a także szeroko pojętej współpracy instytucjonalnej w Salzburgu, wraz z ich skutkami, można wyciągnąć kilka wniosków.

1. Placówka funkcjonuje zgodnie w środowisku naturalnym, zgodnie $\mathrm{z}$ zasadami taoizmu.

2. Jej działania opierają się na filarach łączących elementy edukacyjne z zabawa, integracją i wspieraniem rozwoju jednostki.

3. Wychowawcy Insel zwracają uwagę na znaczenie wpływu jednostki oraz jej społecznych możliwości w obrębie grupy.

4. Uczelnie pedagogiczne w Austrii kładą nacisk na praktyczne przygotowanie do zawodu - stąd pojawiają się szczegółowe wytyczne dotyczące posiadania konkretnych umiejętności pracy z dziećmi.

5. Ustawodawca wymienia typy placówek oraz ilość godzin praktyk, stażu, które upoważniają do podjęcia pracy zawodowej.

6. Istnieje ścisła współpraca pedagogów Wyższej Uczelni Pedagogicznej w Salzburgu z Insel, VS (Szkołą Ponadpodstawową) i HS (Szkoła Podstawowa).

7. Ośrodek opiekuńczy jest zarazem miejscem praktycznego kształcenia przyszłych pedagogów. Został strukturalnie zaplanowanym, naturalnym przedłużeniem etapu nauczania - stanowi pomost pomiędzy kształceniem a zatrudnieniem.

\section{Zusmmenfassung}

\section{DAS SYSTEM DER NACHMITTAGSBETREUUNG AM BEISPIEL DER ANSTALT: INSEL-HAUS DER JUGEND IN SALZBURG}

Der Text "Das System der Nachmittagsbetreuung am Beispiel der Anstalt: Insel - Haus der Jugend in Salzburg" befasst sich mit der Analyse der Struktur, der Organisation und mit den Richtlinien der Erziehungsarbeit in der Anstalt der Nachmittagsbetreuung, die in der Gemeinde Salzburg wirkt. Der Text besteht aus zwei eng verbundenen Teilen.

In dem ersten Teil sind grundlegende Probleme der Nachmittagsbetreuung in Österreich am Beispiel der Gemeinde Salzburg dargestellt:

- Der zweite Teil beschäftigt sich mit der Struktur der Anstalt (u.a. mit ihren Zielen, Aufgaben, Funktionen und mit dem Innenstatut). Die Anstalt bietet die Nachmittagsbetreuung für Kinder im Alter von 5 bis 15 Jahre im Rahmen der Freizeitpädagogik an, die als eine Subdisziplin der Pädagogik gilt.

- Die Richtlinien der Anstalt haben sich im Laufe der Zeit nicht verändert. Sie hat den Kindern immer geholfen, sie bei der Entwicklung ihres Potentials und ihrer Fähigkeiten unterstützt und im Unterricht für Unterhaltung, Spiel und Sport gesorgt. 
- Zu den wichtigsten Bildungszielen der Anstalt gehören:

- Konzentration auf den Einzelnen und dessen soziales Potential im Rahmen der Gruppe;

- Individualisierung des sozialen Lernprozesses - Differenzierung sowohl auf dem individuellen als auch auf dem Gruppenniveau.

- Die Tätigkeit dieser Anstalt beruht auf drei Prinzipien, die die Arbeit der Betreuer bestimmen, und zwar:

- Lernen und Spielen;

- Gemeinsames Aufwachsen und Integration;

- Förderung der Menschen und Erweiterung der Perspektiven.

An die o.g. Probleme knüpft der zweite Teil des Textes. Er beschreibt Kontakte der Anstalt mit Institutionen, die mit ihrer pädagogischen Tätigkeit verbunden sind, die für das Umfeld der Schulen und Hochschulen der Gemeinde Salzburg vorbereitet ist. Diese Kontakte beinflussen nicht nur die Effekivität des Erziehungsprozesses in der Anstalt, sondern auch die Qualität der praktischen Vorbereitung ihrer Pädagogen. Gesetzliche Lösungen bestimmen sowohl die Kontinuität der akademischen Bildung, der praktischen Vorbereitung für den Beruf als auch die Kontinuität der bewußten Leitung des Erziehungs- und Bildungsprozesses der in der Anstalt betreuten Kinder. 